\title{
Hereditary cerebral amyloid angiopathy, Piedmont-type mutation
}

Mariel G. Kozberg, MD, PhD, Susanne J. van Veluw, PhD, Matthew P. Frosch, MD, PhD, and Steven M. Greenberg, MD, PhD

Neurol Genet 2020;6:e411. doi:10.1212/NXG.0000000000000411
Correspondence

Dr. Kozberg

mkozberg@mgh.harvard.edu

\section{Abstract}

\section{Objective}

We present here a case report of a patient with a family history of intracerebral hemorrhages (ICHs) who presented with multiple large lobar hemorrhages in rapid succession, with cognitive sparing, who was found to have a mutation in the $\beta$-amyloid coding sequence of amyloid precursor protein (Leu705Val), termed the Piedmont-type mutation, the second ever reported case of this form of hereditary cerebral amyloid angiopathy (CAA).

\section{Methods}

Targeted pathologic examination was performed aided by the use of ex vivo MRI.

\section{Results}

Severe CAA was observed mainly involving the leptomeningeal vessels and, to a far lesser extent, cortical vessels, with no amyloid plaques or neurofibrillary tangles.

\section{Conclusions}

This leptomeningeal pattern of $\beta$-amyloid deposition coupled with multiple large hemorrhages demonstrates unique pathophysiologic characteristics of CAA associated with the Piedmonttype mutation, suggesting a potential association between leptomeningeal CAA and larger ICHs. 


\section{Glossary}

APP = amyloid precursor protein; $\mathbf{C A A}=$ cerebral amyloid angiopathy; $\mathbf{G R E}=$ gradient echo; $\mathbf{I C H}=$ intracerebral hemorrhage; TSE $=$ turbo spin echo.

Cerebral amyloid angiopathy (CAA) is a disorder in which $\beta$-amyloid peptide is deposited in leptomeningeal and cortical vessels of the brain. This deposition is associated with both cortical microbleeds and large lobar intracerebral hemorrhages (ICHs); however, precise mechanisms leading to vessel rupture remain undetermined. Although some degree of CAA is commonly observed at routine neuropathologic examination, hereditary CAA is relatively rare and typically more severe than sporadic CAA. A number of mutations involving both the coding and noncoding regions of amyloid precursor protein (APP) have been described, each with distinct phenotypes and pathologic features. ${ }^{1-4}$

The Piedmont-type mutation is a mutation in the coding region of APP (Leu705Val). ${ }^{5}$ The single reported postmortem brain with this mutation demonstrated vascular $\beta$-amyloid pathology without neurofibrillary tangles or $\beta$-amyloid plaques within the brain parenchyma.

We present here a second, independent case with similar pathologic observations and focus on unique clinical and pathologic features not previously described.

\section{Methods}

\section{Neuropathologic examination and ex vivo MRI}

Brain autopsy was performed after organ donation (with a 67-hour postmortem interval before brain extraction). The brain was fixed in $10 \%$ formalin, and the hemispheres were separated by a midsagittal cut. The left hemisphere underwent standard neuropathologic evaluation. The right hemisphere was fixed for 2 months in 10\% formalin and then

Figure 1 Clinical data

A

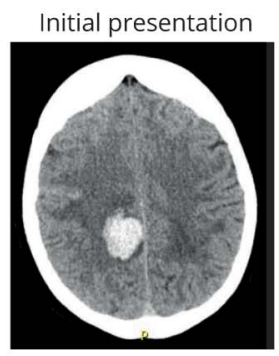

1 month

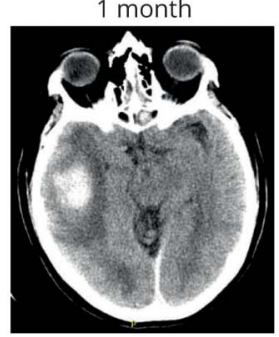

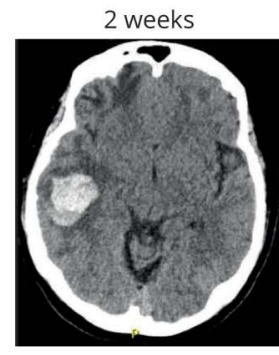

3 months

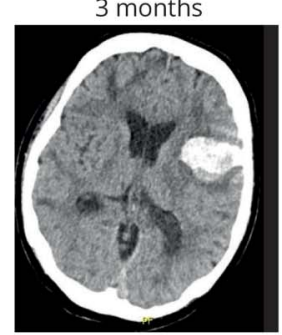

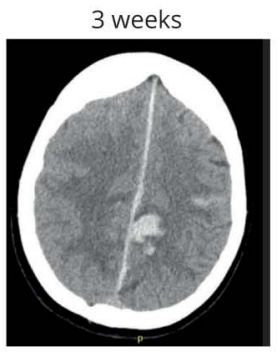

4 months

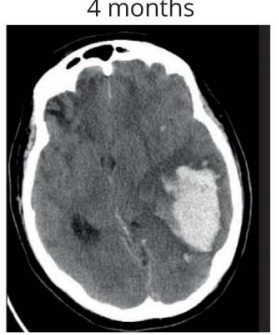

B
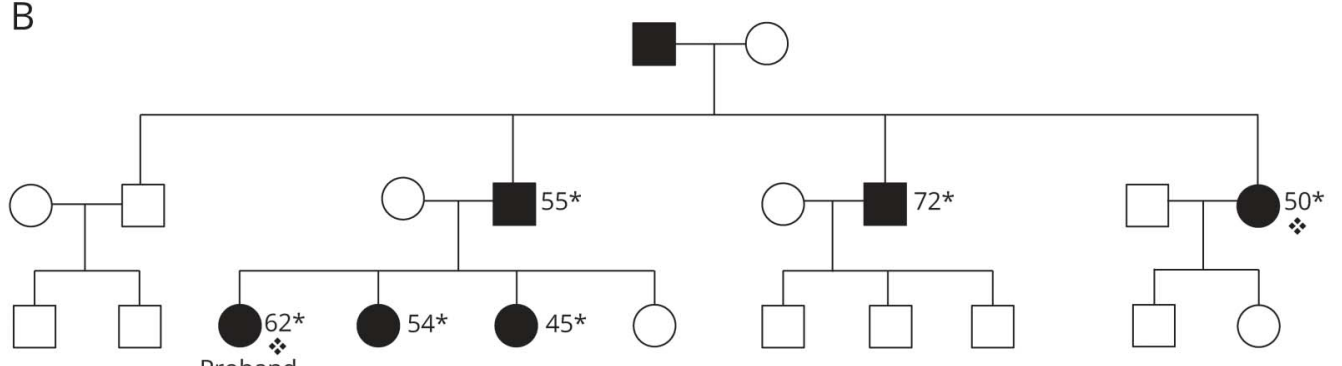

Proband

* Age at time of first symptomatic hemorrhage

(A) CT scans demonstrating the time course of patient's multiple lobar ICHs. (B) Pedigree of proband's family. Black circles/squares represent family members with ICHs. Gray square represents a family member who died of stroke in his 60s, unknown if stroke was hemorrhagic or ischemic. Diamond symbol indicates family members with autopsies confirming cerebral amyloid angiopathy. ${ }^{*}$ Age at time of first symptomatic hemorrhage. ICH = intracerebral hemorrhage. 


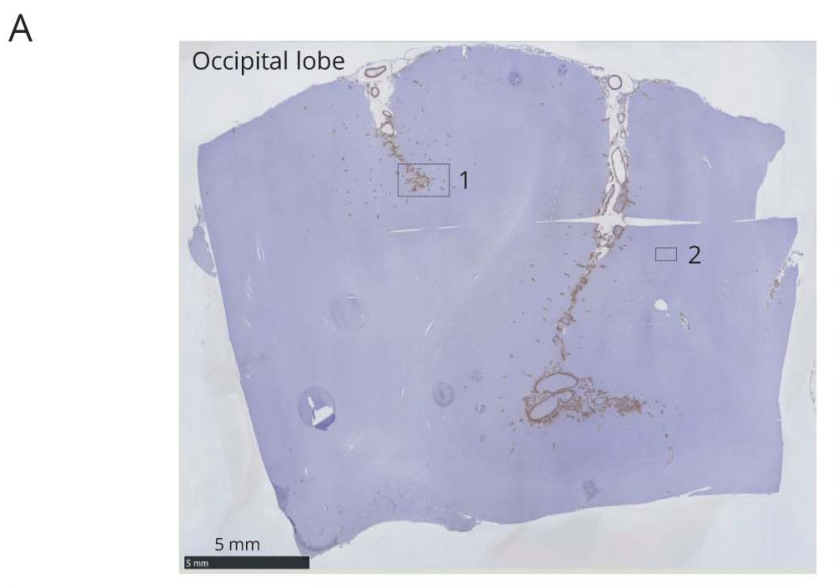

B

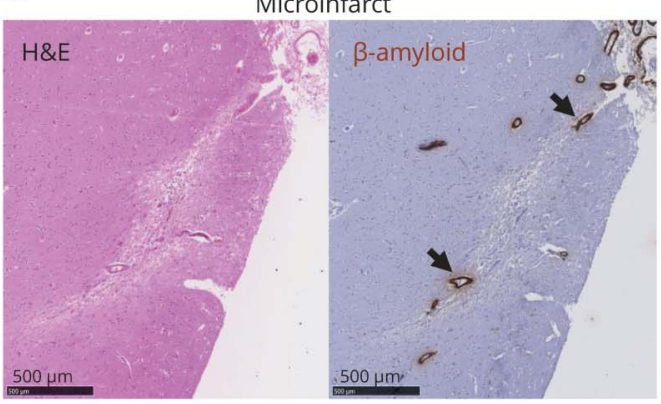

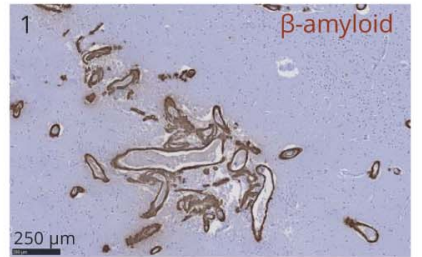

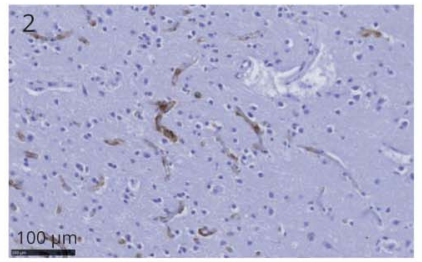

Microbleed

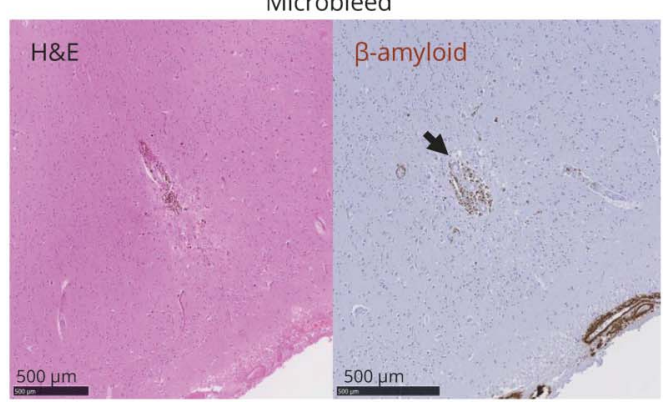

(A) $\beta$-amyloid staining revealed severe widespread leptomeningeal CAA with relative sparing of the cortical vessels. CAA was observed in capillaries in the occipital lobe (bottom right panel). (B) Cortical microinfarct and cortical microbleed shown with both $\mathrm{H} \& \mathrm{E}$ and $\beta$-amyloid staining. $\beta$-amyloid staining demonstrated $\beta$-amyloid deposition in the walls of the vessels supplying the infarcted area (denoted by arrows). No $\beta$-amyloid staining was observed in the segment of vessel with a microbleed (denoted by arrow). CAA = cerebral amyloid angiopathy; H\&E = hematoxylin and eosin.

scanned intact with high-resolution ex vivo $3 \mathrm{~T}$ MRI, using gradient echo (GRE) and turbo spin echo (TSE) sequences, as previously described. ${ }^{6}$

Afterward, the right hemisphere was cut in coronal slabs and the samples were taken from frontal, parietal, temporal, and occipital lobes for histopathologic evaluation including standard hematoxylin and eosin ( $\mathrm{H} \& \mathrm{E})$ staining and immunohistochemistry against $\beta$-amyloid (clone 6F/3D, Agilent). Additional samples were taken from the areas with cortical microbleeds on MRI, and serial sectioning was performed to evaluate the ruptured blood vessels.

\section{Genetic analysis}

Genetic sequencing was performed through Athena Diagnostics ADmark APP DNA Sequencing Test and Duplication Test (test code 168), which confirmed a heterozygous missense mutation in APP (c.2113C>G; p.Leu705Val).

\section{Standard protocol approvals, registrations, and patient consents}

The Massachusetts General Hospital institutional review board approved this study. Autopsy was performed with informed consent of the patient's family.

Family history was obtained through interviews with family members.

\section{Data availability}

All data not published within this article will be shared on request from any qualified investigator.

\section{Results}

\section{Clinical data}

A 62-year-old right-handed woman with a history of paroxysmal atrial fibrillation (not on anticoagulation or antiplatelet agents) presented with a severe right-sided retro-orbital headache, word-finding difficulty, and issues with balance. She reported one previous episode of 1-2 hours of confusion in the preceding months and 2 previous episodes of spreading sensory symptoms involving tingling on her left side in varied distributions, each lasting approximately 10 minutes. A CT head demonstrated a right-sided parietal $\mathrm{ICH}$ (figure 1A, upper left panel) and a remote right frontal ischemic infarct. After this event, her symptoms fully resolved and she continued working as a nurse.

Over the next 3 months, she was hospitalized 4 more times for recurrent lobar ICHs (right temporal, left cingulate/left frontal, right medial temporal, and left frontal respectively; figure 1A). After each hospitalization, her cognition was initially impaired but quickly improved to close to her baseline. Four months after initial presentation, she was found down and 
a CT head demonstrated a new right temporoparietal $\mathrm{ICH}$ with associated midline shift (figure 1A; bottom right panel). Her examination was consistent with brain death.

The proband had a family history of $\mathrm{ICH}$ consistent with autosomal dominant inheritance, including her grandfather, her father and 2 of his siblings, and 2 of the patient's 3 siblings (figure 1B). Her paternal family ancestry traces back to England and Wales, with no known Italian lineage or overlap with the single previously reported family with the Piedmonttype mutation ${ }^{5}$; however, shared ancestry was not assessed through further genetic analysis. Similar to the proband, all affected family members were working and their cognitive baselines before their initial ICHs. Autopsy results of the proband's aunt confirmed CAA. Genetic testing has not been performed on other family members to our knowledge.

\section{Pathologic examination}

The brain weight on autopsy was within the normal range for women $(1,550 \mathrm{~g})$, with no evidence of significant atrophy. Immunohistochemistry against $\beta$-amyloid revealed widespread severe CAA, most pronounced in leptomeningeal vessels, although also observed in cortical vessels and capillaries (figure 2A). Vascular thickening and focal splitting of the vessel wall, consistent with Vonsattel grade $3 / 4{ }^{7}$ were frequently observed in the leptomeningeal vessels and occasionally in the cortical vessels. Immunohistochemistry against hyperphosphorylated tau using AT8 antibody was negative. No evidence of inflammation was observed. No hypertensive arteriopathy was observed in the larger vessels or the basal ganglia.

The GRE scan of the right hemisphere revealed 51 cortical microbleeds and 3 sites of cortical superficial siderosis. These hemorrhagic lesions were distributed across the cortex, with no specific lobar predilection (figure 3 ). The detection of cortical microinfarcts on TSE was hampered by widespread diffuse hypoxic-ischemic tissue injury related to the long postmortem interval in the setting of organ donation.

H\&E-stained sections from each lobe were screened for old microinfacts. Four cortical microinfarcts were identified in total (across all 4 sections), fewer than typically observed in cases with sporadic CAA using similar methodology. ${ }^{8}$ The cortical vessels associated with each microinfarct had substantial $\beta$-amyloid in their walls (figure $2 \mathrm{~B}$ ). Serial sectioning of MRI-guided samples yielded 3 microbleeds ( 2 recent, one old). The walls of vessels associated with microbleeds did not contain $\beta$-amyloid (figure $2 \mathrm{~B}$ ).

\section{Discussion}

The neuropathologic evidence shown here, together with a previously reported unrelated individual, ${ }^{5}$ suggests that the Piedmont-type mutation in APP leads to a distinct form of

Figure 3 High-resolution ex vivo MRI

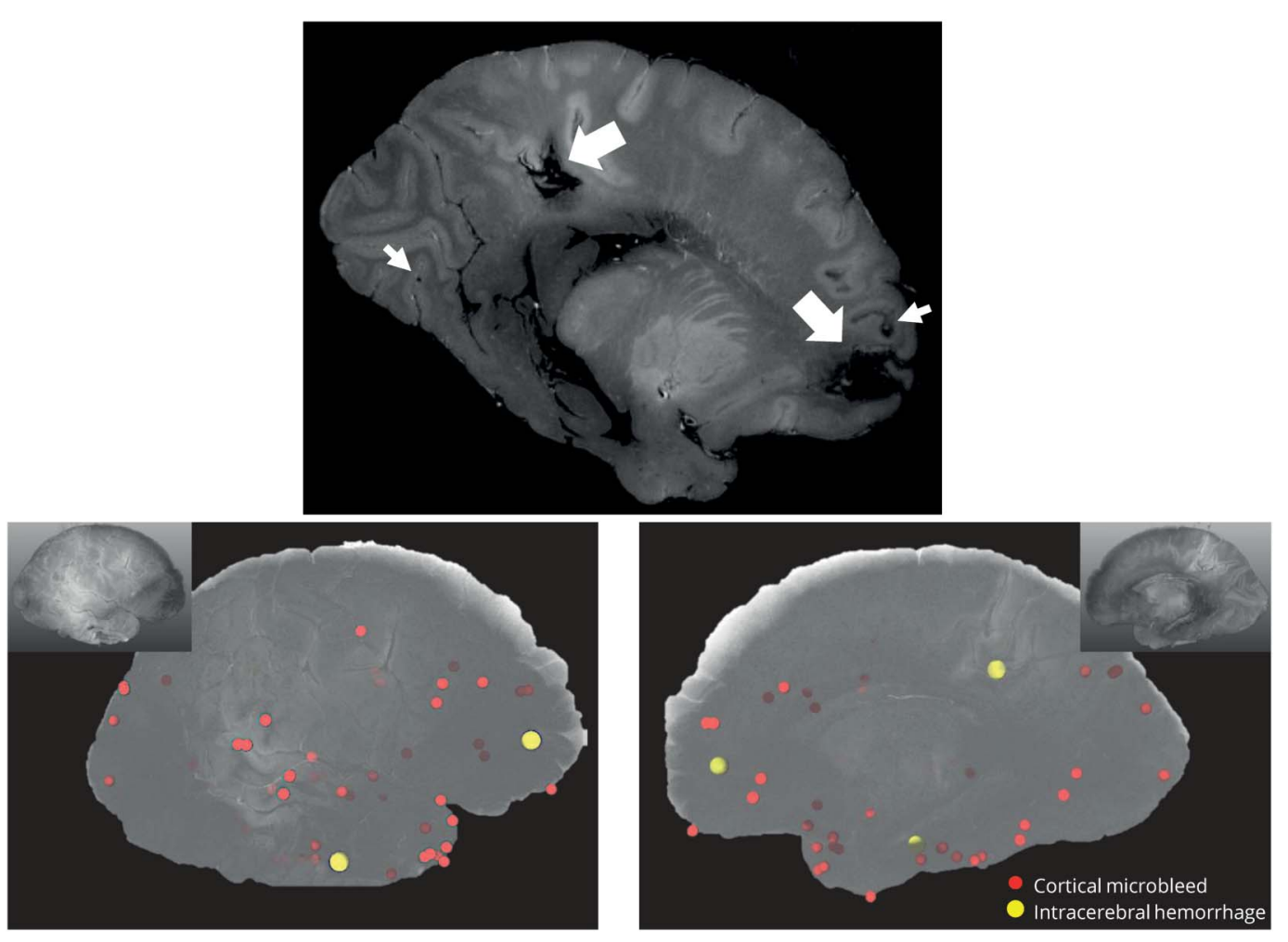

Top, ex vivo GRE scan, sagittal view. Large arrows point to lobar ICHs, smaller arrows to cortical microbleeds. Bottom, 3D representation of cortical microbleeds (red) and larger ICH (yellow) locations, insets with scans of the cortical surface. GRE = gradient echo; ICH = intracerebral hemorrhage. 
hereditary CAA with exclusively vascular $\beta$-amyloid deposition. We present a patient with a confirmed Leu705Val mutation in APP, who suffered from multiple large lobar ICHs in rapid succession, with no preceding cognitive decline and good cognitive recoveries from her hemorrhages until her terminal event. Affected family members had similar clinical courses, with no cognitive decline preceding their lobar ICHs. This clinical course is similar to that of the previously reported Italian family with this mutation ${ }^{5}$ and distinct from other hereditary forms of CAA, suggesting that it is characteristic of this mutation.

We demonstrated that $\beta$-amyloid deposits were primarily found within the leptomeningeal vessels, with relative sparing of the cortical vasculature. Based on this finding and the rapid pace of recurrent hemorrhages, we hypothesize that extensive leptomeningeal involvement may predispose patients with the Piedmont-type mutation to a more severe hemorrhagic phenotype than sporadic CAA and some other hereditary forms of CAA.

The MRI-guided neuropathologic analysis offers potential insights into the mechanisms of CAA-related hemorrhage. We examined vessels associated with cortical microbleeds and observed no $\beta$-amyloid in the vessels at the bleeding site. This finding is consistent with previous observations in sporadic CAA, ${ }^{8,9}$ suggesting a mechanism in which severely affected vessel segments undergo remodeling entailing loss of $\beta$-amyloid deposits before hemorrhage. ${ }^{8}$ Determining the exact rupture site for leptomeningeal bleeds is more challenging because these hemorrhages are often larger and more dispersed with significant damage to the surrounding tissue. It is therefore unclear whether leptomeningeal vessel hemorrhages follow the same proposed pathophysiologic mechanism as smaller cortical microbleeds, a topic for future investigations.

Qualitative assessment of H\&E-stained sections suggested fewer chronic microinfarcts than typical in sporadic CAA. ${ }^{8}$ Similar to observations in sporadic CAA, the vessels feeding the infarcted tissue demonstrated increased local $\beta$-amyloid burden. ${ }^{8}$ These findings suggest that the relative sparing of the cortical vasculature from CAA may lead to fewer microinfarcts in patients with the Piedmont mutation, a factor likely contributing to the lack of cognitive impairment in these patients (in addition to the absence of plaques and tangles).

Our findings demonstrate that the Piedmont-type mutation leads to specific accumulation of $\beta$-amyloid within leptomeningeal vessels. Further investigation into the molecular properties of the mutated $\beta$-amyloid has the potential to provide valuable insights into the mechanisms of $\beta$-amyloid deposition and vessel damage.

\section{Acknowledgment}

The authors thank Karen Bechdol for researching and sharing the family history presented in this manuscript.

\section{Study funding}

The authors acknowledge support from the National Institutes of Health grants: R01AG26484 (Greenberg), P30AG062421 (Frosch), and K99AG059893 (van Veluw).

\section{Disclosure}

Disclosures available: Neurology.org/NG.

\section{Publication history}

Received by Neurology: Genetics November 27, 2019. Accepted in final form January 27, 2020.

Appendix Authors

\begin{tabular}{lll}
\hline Name & Location & Contribution \\
\hline $\begin{array}{l}\text { Mariel } \\
\text { Mozberg, } \\
\text { MD, PhD }\end{array}$ & $\begin{array}{l}\text { Brigham and Women's } \\
\text { Hospital; Massachusetts } \\
\text { General Hospital; Harvard } \\
\text { Medical School, Boston }\end{array}$ & $\begin{array}{l}\text { Data collection and } \\
\text { analysis, drafting, and } \\
\text { revision of the manuscript. }\end{array}$ \\
\hline $\begin{array}{l}\text { Susanne } \\
\text { van Veluw, } \\
\text { PhD }\end{array}$ & $\begin{array}{l}\text { Massachusetts General } \\
\text { Hospital; Harvard Medical }\end{array}$ & $\begin{array}{l}\text { Data collection and } \\
\text { analysis, drafting, and } \\
\text { revision of the manuscript. }\end{array}$ \\
$\begin{array}{l}\text { Matthew } \\
\text { Frosch, MD, } \\
\text { PhD }\end{array}$ & $\begin{array}{l}\text { Massachusetts General } \\
\text { Hospital; Harvard Medical }\end{array}$ & $\begin{array}{l}\text { Data collection and } \\
\text { analysis, revision of the } \\
\text { manuscript. }\end{array}$ \\
$\begin{array}{l}\text { Stevool, Boston } \\
\text { Greenberg, } \\
\text { MD, PhD }\end{array}$ & $\begin{array}{l}\text { Mospachusetts General } \\
\text { School, Boston }\end{array}$ & $\begin{array}{l}\text { Clinical care, data } \\
\text { collection and analysis, } \\
\text { drafting, and the revision } \\
\text { of manuscript. }\end{array}$ \\
\hline
\end{tabular}

\section{References}

1. Biffi A, Greenberg SM. Cerebral amyloid angiopathy: a systematic review. J Clin Neurol 2011;7:1-9.

2. Bornebroek M, Jonghe CDe, Haan J, et al. Hereditary cerebral hemorrhage with amyloidosis Dutch type (AbetaPP 693): decreased plasma amyloid-beta42 concentration. Neurobiol Dis 2003;14:619-623.

3. Greenberg SM, Shin Y, Grabowski TJ, et al. Hemorrhagic stroke associated with the Iowa amyloid precursor protein mutation. Neurology 2003;60:1020-1022.

4. De Jonghe C, Zehr C, Yager D, et al. Flemish and Dutch mutations in amyloid beta precursor protein have different effects on amyloid beta secretion. Neurobiol Dis 1998;5:281-286.

5. Obici L, Demarchi A, De Rosa G, et al. A novel A $\beta P P$ mutation exclusively associated with cerebral amyloid angiopathy. Ann Neurol 2005;58:639-644.

6. van Veluw SJ, Reijmer YD, Van Der Kouwe AJ, et al. Histopathology of diffusion imaging abnormalities in cerebral amyloid angiopathy. Neurology 2019;92:E933-E943.

7. Vonsattel JPG, Myers RH, Tessa Hedley-Whyte E, Ropper AH, Bird ED, Richardson EP. Cerebral amyloid angiopathy without and with cerebral hemorrhages: a comparative histological study. Ann Neurol 1991;30:637-649.

8. van Veluw SJ, Scherlek AA, Freeze WM, et al. Different microvascular alterations underlie microbleeds and microinfarcts. Ann Neurol 2019;86:279-292.

9. van Veluw SJ, Kuijf HJ, Charidimou A, et al. Reduced vascular amyloid burden at microhemorrhage sites in cerebral amyloid angiopathy. Acta Neuropathol 2017;133: 409-415. 


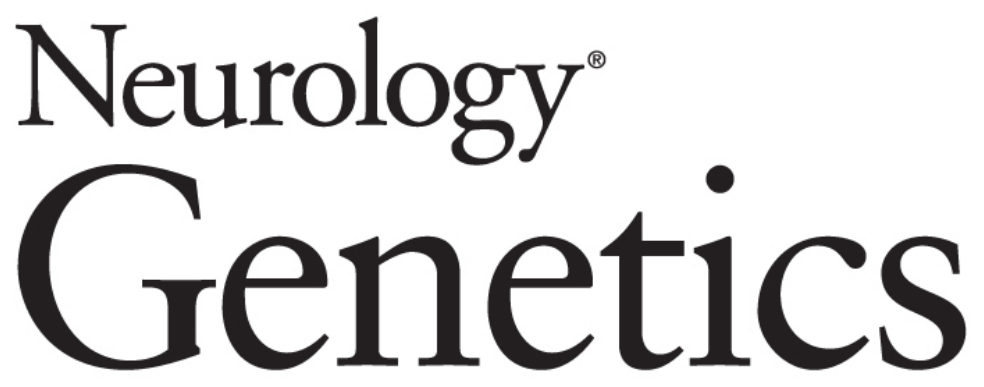

Hereditary cerebral amyloid angiopathy, Piedmont-type mutation Mariel G. Kozberg, Susanne J. van Veluw, Matthew P. Frosch, et al. Neurol Genet 2020;6;

DOI 10.1212/NXG.0000000000000411

This information is current as of March 13, 2020

Neurol Genet is an official journal of the American Academy of Neurology. Published since April 2015, it is an open-access, online-only, continuous publication journal. Copyright Copyright $@ 2020$ The Author(s). Published by Wolters Kluwer Health, Inc. on behalf of the American Academy of Neurology.. All rights reserved. Online ISSN: 2376-7839.

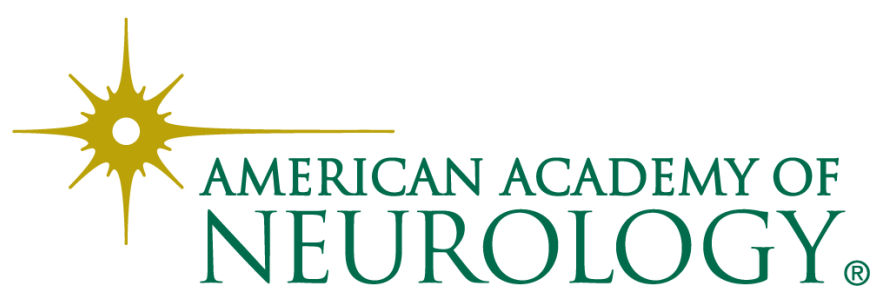




\section{Updated Information \& Services}

References

Citations

Subspecialty Collections

Permissions \& Licensing

Reprints including high resolution figures, can be found at: http://ng.neurology.org/content/6/2/e411.full.html

This article cites 9 articles, 0 of which you can access for free at: http://ng.neurology.org/content/6/2/e411.full.html\#\#ref-list-1

This article has been cited by 1 HighWire-hosted articles: http://ng.neurology.org/content/6/2/e411.full.html\#\#otherarticles

This article, along with others on similar topics, appears in the following collection(s):

\section{All Cerebrovascular disease/Stroke}

http://ng.neurology.org//cgi/collection/all_cerebrovascular_disease_str oke

All Cognitive Disorders/Dementia

http://ng.neurology.org//cgi/collection/all_cognitive_disorders_dementi a

Intracerebral hemorrhage

http://ng.neurology.org//cgi/collection/intracerebral_hemorrhage

MRI

http://ng.neurology.org//cgi/collection/mri

Information about reproducing this article in parts (figures,tables) or in its entirety can be found online at:

http://ng.neurology.org/misc/about.xhtml\#permissions

Information about ordering reprints can be found online:

http://ng.neurology.org/misc/addir.xhtml\#reprintsus

Neurol Genet is an official journal of the American Academy of Neurology. Published since April 2015, it is an open-access, online-only, continuous publication journal. Copyright Copyright ( 2020 The Author(s). Published by Wolters Kluwer Health, Inc. on behalf of the American Academy of Neurology.. All rights reserved. Online ISSN: 2376-7839.

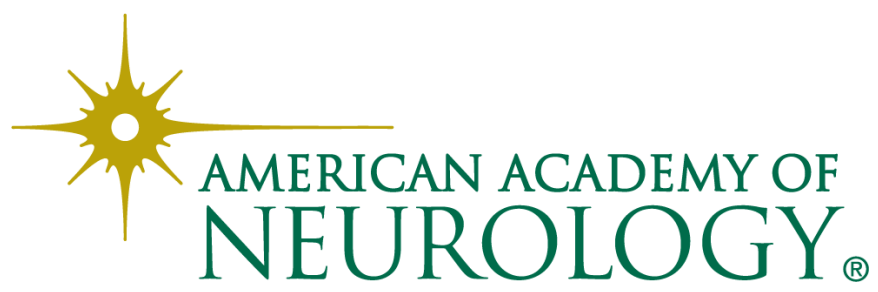

